\title{
Remember it with love: Effects of love priming on text recall
}

\author{
LUBOMIR LAMY, NICOLAS GUÉGUEN and JACQUES FISCHER-LOKOU
}

\begin{abstract}
Three studies investigated the effects of love priming on text recall. In Study 1, love was induced through exposition to scrambled words and letters semantically associated with love. It was predicted and found that participants induced with the idea of love, as compared to a control group, had better recall of a problem-solution text. Studies 2 and 3 verified that this effect may be generalized to other texts, simply due to the presence of the word love. It was also found that the priming of love increased interest in the material, but had no effect on mood. These results suggest that love may act as an emotion schema (Izard, 2007), with increased motivation and activation of approachoriented responses.
\end{abstract}

Key words: love, priming, text recall, interest

Common sense often presents love and science, feelings and reason, as opposite realities: one person reasons without her heart, another has his reasoning impaired by love. More specifically, emotion is thought to lead to a narrowed focus of attention, with enhanced information recall being associated with experiences of emotional significance (Levine \& Edelstein, 2009). Moreover, the ability to focus attention is reduced to such an extent by the experience of emotion that other processes that require this capacity can be impaired.

Love has been characterized as a constellation of emotions and as a motivational experience, both definitions being overlapping (Aron et al., 2008). Love does not imply a basic, distinct emotion, but it generates multiple emotions (joy, contentment, sadness, jealousy) that are related to a person's level of satisfaction. As a motivational state, love is the search for the presence of and affection from a loved one. Similarly, love can be conceived as an amalgam of discrete positive emotions that broaden the scopes of attention, cognition, and action (Fredrickson, 2001). The effect of love, like other positive emotions, is, thus, to arouse enthusiasm and interest, to provoke reaction and decision, and

Lubomir Lamy, Université Paris Descartes, Sorbonne Paris Cité, IUT de Paris, CS, 143 avenue de Versailles, 75016 Paris, France. E-mail: lubomir.lamy@parisdescartes.fr (the address for correspondence);

Nicolas Guéguen, Université de Bretagne-Sud, France;

Jacques Fischer-Lokou, Université de Bretagne-Sud, France. thus, prompt individuals to take part in activities and to take an interest in ongoing information.

Despite these findings, some questions remain. Do positive emotions enhance attention and cognitive processing only when emotional stimuli are at stake, or is it possible to elicit activation of cognitive processing with non-emotional stimuli? Is it possible to improve cognitive functioning when the mere concept of love is substituted for "real" feelings of love directed towards another individual, i.e., when love is manipulated as an independent variable?

\section{Love priming versus inducing}

In psychology literature, the word priming remains somewhat ambiguous because it may refer to two distinct techniques. The semantic priming technique (Meyer \& Schvaneveldt, 1971; Neely, 1976) implies that a stimulus word or sentence is briefly (e.g., $50 \mathrm{~ms}$ ) presented, followed (e.g., $150 \mathrm{~ms}$ ) by a mask that reduces the visibility of stimulus remnants. The participant is then supraliminally $(t \leq 1500$ $\mathrm{ms}$ ) exposed to another stimulus, which is either semantically connected, or not, to the first stimulus. Research involving this technique has strongly established that a word response (e.g., naming task, lexical decision task, semantic categorization task) will be facilitated if both stimuli are semantically connected.

More recently, however, the words priming and prime have been dissociated from the semantic priming technique. Among social cognitive research, these words commonly 
refer to the mere semantic induction of a concept. Participants are exposed to words or semantic categories that are supposed to trigger cognitive, emotional, or behavioral effects. Within this line of research, the focus is no longer on the semantic links between two concepts, but on the effects of one concept. For example, in Bargh, Chen, and Burrows's (1996) Experiments 1 and 2, priming manipulation took the form of scrambled-sentence tasks. Participants primed with the concept of rudeness interrupted the experimenter more quickly than those primed with the concept of politeness (Experiment 1); participants primed with words related to the stereotype of old-age walked more slowly when leaving the place where the experiment took place, compared to those exposed to words unrelated to the stereotype of old-age (Experiment 2). In a recent research conducted by Förster, Özelsel, and Epstude (2010), priming was manipulated by asking participants to imagine a walk with a person they are in love with (love priming), a walk with an old friend (friendship priming), or a one-night stand with a person they are attracted to (lust priming). This love priming condition is close to the semantic induction of love used in a set of studies (Fischer-Lokou, Lamy, \& Guéguen, 2009; Lamy, Fischer-Lokou, \& Guéguen, 2008, 2009) where participants were asked to retrieve the memory of a partner they had been deeply in love with. In the present research, we shall not refer to semantic priming, but to priming or semantic induction procedures, i.e., when participants are exposed to a word or semantic category that is supposed to influence their cognitive, behavioral, or emotional responses.

Despite numerous studies investigating the effects of emotional stimuli priming, little attention has been paid to the priming of love. Most studies of subliminal priming are limited to the priming of positive versus neutral, or negative, emotional states. In some cases, however, discrete emotions (mostly negative ones) have been tested. For example, individuals primed with guilt were more helpful than those primed with sadness (Zemack-Rugar, Bettman, \& Fitzsimons, 2007) and individuals primed with attachment security were more positive in their affective reactions to neutral stimuli (Mikulincer, Hirschberger, Nachmias, \& Gillath, 2001). When induced to consciously remind themselves of a friend, compared to a co-worker, participants showed increased helping behavior (Fitzsimons \& Bargh, 2003). The relationship between semantic induction of love and helpfulness has also been investigated in natural, urban settings. When primed with the concept of love, through a brief questionnaire, and asked to remember a loved one, men were more helpful towards women passersby requiring assistance (Fischer-Lokou et al., 2009; Lamy et al., 2008, 2009). These studies showed that the concept of love can have a powerful inductive effect on prosocial behavior, particularly in the case of chivalrous helping (Dovidio \& Penner, 2001). When strong semantic associations exist between the concepts used in the priming event, love can still be used indirectly and outside of any romantic context to engender positive behavioral effects, even in participants who are unaware of a semantic connection with the concept of love (Lamy, Fischer-Lokou, \& Guéguen, 2010).

Priming with love is thought to automatically trigger a global, creative thought-processing style, whereas priming with sex activates a local, detail-oriented processing style (Förster, Epstude, \& Özelsel, 2009). Moreover, participants primed with love, compared to sex, have a more positivist regard for their romantic partner and a lack of differentiation (halo effect) in their partner's perception (Förster et al., 2010). Previous research, however, has not addressed the question of whether love priming can influence text memory.

\section{Love as interference}

Here, we were interested in how recall of information could be increased by the semantic induction of love. We reasoned that love, being considered as a positive, highly arousing emotion (Talarico, Berntsen, \& Rubin, 2009), may generate emotional interest (Kintsch, 1980) in the same way as other concepts do (e.g., sex, violence), by capturing and drawing from, almost universally, an individual's attentional resources. Interest, in turn, has been found to involve consistently increased attention, cognitive functioning, and learning (Hidi, 2001). As such, we expected recall performance relative to a specific text to be improved when love was semantically induced, compared to an emotionless control condition. In this context, however, one must not overlook the possible interference that may be conveyed by an emotional concept such as love. Previous research has found that emotional stimuli capture and hold our attention, and that such emotional interference may impair task performance (Huang, Baddeley, \& Young, 2008; Ihssen \& Keil, 2009). In addition, cognitive interference consists of intrusive, off-task thoughts that may also compete with relevant cognitive processing and affect working memory and recall performance (Coy, O’Brien, Tabaczynski, Northern, \& Carels, 2011; Ellis, Moore, Varner, Ottaway, \& Becker, 1997). The resource allocation model (Ellis \& Ashbrook, 1988) suggests that emotional states draw on a part of an individual's ability to focus attention, weakening performance on tasks that require concerted attention (e.g., recall of information). In sum, if the concept of love acts as an attention magnet (Laney, Campbell, Heuer, \& Reisberg, 2004), it might: (a) induce increased attention and interest, which will enhance cognitive processing; and (b) interfere with the current task at hand and thus impair information processing.

\section{EXPERIMENT 1}

To circumvent this possible interference effect, we activated the concept of love by means of scrambled words and letters. Our procedure was designed to focus participants' 
attention away from the possible meanings of these stimuli, thereby minimizing the effect of the emotional concept of love in capturing participants' attention to the detriment of the problem-solution text. Using a problem-solution text allowed us to evaluate participant's recall of information, both at a surface or factual level of comprehension, and at a deeper level of comprehension. We predicted that participants who were semantically induced with love, as compared to a non-emotional concept, would have greater interest in the current task, and thus would show improved performance in remembering the text. We tested this hypothesis in an a priori emotionless and passionless context, where business students were solicited to participate in a simple memory experiment in relation to a scientific topic. Using symbols and terms, unrelated to the scientific text yet clearly (and thus consciously) visible to the participants, we devised a technique to divert participants' attention away from any possible semantic meanings. As our hypothesis was never investigated in previous research, we designed an original setting to test for possible effects of the concept of love on text memory.

\section{METHOD}

\section{Participants}

One hundred twenty two undergraduate Business students (34 male) from the University of South Paris, France, aged 18 and 19, volunteered to take part in a "study of human memory." At the beginning of the semester, these students had been randomly assigned to six groups (ranging in size from 19 to 21 participants), and when the experiment took place these groups were subsequently randomly assigned to either the experimental (love) condition (3 groups) or the control condition (3 groups). A preliminary analysis showed that there were no significant differences in the grades obtained by the participants in the experimental versus the control condition, with regard to their university courses during the semester at the time of the experiment.

\section{Materials}

We used a text presenting hypotheses as to why the dinosaurs became extinct at the end of the Mesozoic era. This problem-solution text is divided into 73 meaning units and was used previously by Querrioux-Coulombier (1988) and Rossi \& Bert-Erboul (1991), together with a corresponding set of questions. This material was constructed initially by Querrioux-Coulombier (1988) to differentiate good and poor comprehenders. In line with Kintsch and van Dijk's (1978) seminal view of microstructure and macrostructure representations, there is a wide agreement that text comprehension and memory involve multilevel representations, such as surface structure, textbase and situation model (Wolfe \& Woodwyk, 2010), or surface representation, propositional representation and mental model (Leopold \& Leutner, 2012). Text memory may relate to details and to the exact wording of the text, i.e., to a surface, microstructure level. It may relate to the main concepts of the text and to its structure, i.e., to the textbase or macrostructure level. Finally, text comprehension and memory may relate to a situation model that consists of knowledge structures representing the gist of the text, and allowing further inferences and adaptation in new contexts. Rossi and Bert-Erboul (1991) designed three sets of questions regarding the dinosaur text. These questions assessed: (a) comprehension of the main topics, or macrostructure, e.g., "Had almost all the dinosaurs disappeared by the end of the Mesozoic era?", "Are movements of the sea accompanied by climate warming?"; (b) comprehension of the arguments presented in the text, e.g., "According to the sea movement hypothesis, did the dinosaurs disappear abruptly at the end of the Mesozoic era?", "Have dinosaur fossils always been found below the iridium layer?"; and (c) comprehension of the details, or microstructure, e.g., "Is the geological site of Gubbio in Spain?", "Was Tyrannosaurus a herbivore?" Comprehension of the arguments was added to the comprehension of the text's microstructure and macrostructure, as Querrioux-Coulombier (1988) and Rossi and Bert-Erboul (1991) reasoned that it is inherent to the comprehension of a scientific text, whereas initial models of comprehension were drawn in the context of narrative texts. And indeed, these authors found that questions assessing argument comprehension were those that best differentiated poor and good comprehenders.

\section{Procedure}

The problem-solution text was presented on a large overhead screen $(2 \times 1.70 \mathrm{~m})$ clearly visible to all participants. The experimenter asked the participants to read the text very carefully and announced that they would be required to answer questions about it. After all participants had finished reading the text (which took 10 to 12 minutes), a set of five letters and ten words mixed together was displayed briefly (150 ms, with a $2 \mathrm{~s}$ latency between two items) on the same screen. The duration of the word and letter display, and the short latency between them, allowed participants to see each word and letter, without enabling them to be sure they had identified any of them when the display was over. In the experimental (love) condition, the five letters were those composing the word "love" in French (A-M-O-U-R). In the control condition, the letters composed the word table (T-A-B-L-E). In the love condition, words that are semantically connected to the concept of love were presented (e.g., heart, together, rose), mixed with filling words (e.g., of, symbol), whereas in the control condition the words were semantically disconnected from each other, and also from the concept of love. In the experimental (love) condition, we avoided words such as passion or marriage that might have triggered identification of the concept of love too easily. In 
both groups, the lists were made up of words with similar consonances, containing the same number of letters. During the overhead projection, the five letters and ten words were shown in random order except for the first element which was always the first letter, A or T, according to the experimental condition. The letters were presented in uppercase and each projected twice, the 10 words in lowercase and were each projected once. To ensure that participants focused their attention away from the meanings of the words and letters displayed, they were asked to count the number of individual letters that appeared on the screen. When all the letters and words had been displayed, and before answering questions about the meaning of the letters and words, the participants were asked to complete the series of 18 questions based on the semantic structure of the problem-solution text. The first six questions dealt with the main topics or macrostructure, followed by six questions about the arguments presented in the text. The final six questions addressed the details in the text or its microstructure. These questions were grouped according to the level of comprehension they assessed, were presented regardless of the chronological appearance of the related information in the text, and were presented in a fixed order to all participants. Each correct answer was rated with one point on the related scale, and thus participants had a 0 to 6 score for macrostructure, for arguments, and for microstructure recall. Participants were then asked to assess the extent to which they felt an interest in the subject of the text (the extinction of dinosaurs), using a scale from zero to ten $(0=$ no interest at all, $10=$ extremely interested $)$. This question was intended as a measure of emotional interest (Harp \& Mayer, 1997) for use in further analysis. Participants were then asked to write down the total number of individual letters they had counted and to list as many of the words among those briefly presented as they could remember. Finally, participants were asked whether they had made a connection between the letters and words and their meanings: "Do you think these words and letters had a general meaning - and if so, which one - or were they just put together without a particular meaning?"

\section{RESULTS}

\section{Text comprehension}

A $2(\operatorname{sex}) \times 2$ (semantic induction) multivariate analysis of variance on the total scores of text comprehension at the macrostructure, argumentation and microstructure levels, yielded significant results for semantic induction (Wilks's $\left.\lambda=.92, F(3,116)=3.09, p<.03, \eta^{2}=.07\right)$, but not for sex $(p>.1)$ or the interaction (Wilks's $\lambda=.94, F(3,116)=2.23$, $p=.08, n s)$. Univariate follow-up showed that participants semantically induced with love scored significantly higher than those in the control (see Figure 1) on the microstructure level, $M=4.83(S D=0.81)$ vs. $M=4.21(S D=1.15), F(1$,

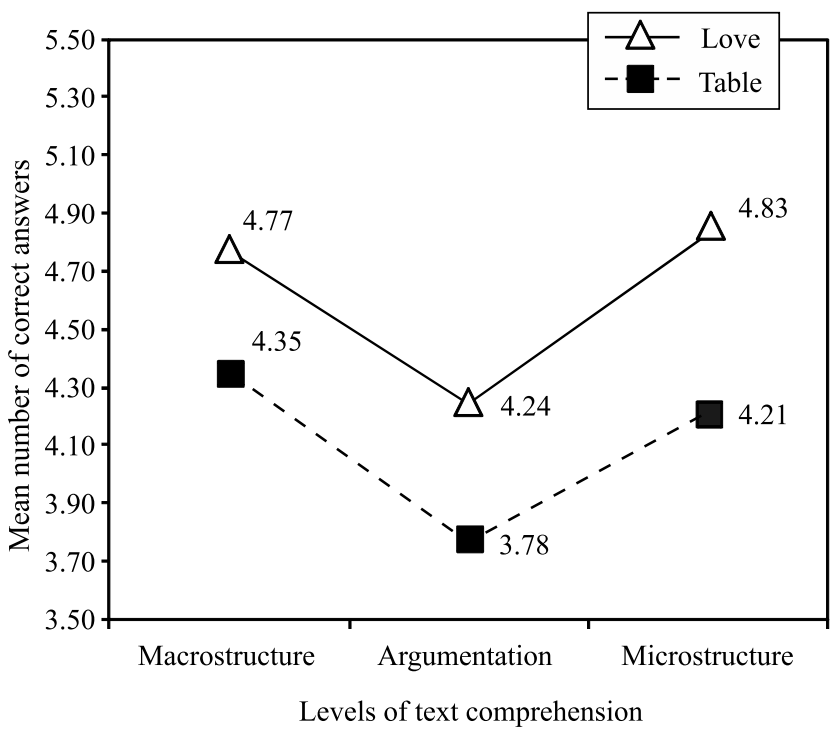

Figure 1. Text comprehension performance as a function of priming and comprehension level $(N=122)$.

$120)=11.94, p<.001, \eta^{2}=.09$, and on the argumentation level, $M=4.24(S D=0.88)$ vs. $M=3.78(S D=1.29), F(1$, $120)=5.28, p<.03, \eta^{2}=.04$. On the macrostructure level, the difference is slightly above the significance level, $M=$ $4.77(S D=1.13)$ vs. $M=4.35(S D=1.31), F(1,120)=3.64$, $p=.058, \eta^{2}=.03$.

\section{Interest regarding the problem-solution text}

The main effect of semantic induction was significant, $F(1,118)=5.67, p<.02, \eta^{2}=.06$, in the $2(\operatorname{sex}) \times 2$ (semantic induction) analysis of variance for interest in the text. More than the participants in the control, those who were semantically induced with the concept of love reported finding the text interesting, $M=6.13, S D=0.31$, vs. $M=5.00$, $S D=0.35$, respectively.

\section{Number of letters retrieved}

A similar 2 (sex) X 2 (semantic induction) analysis of variance performed with the number of letters retrieved by the participants, also yielded a significant main effect of semantic induction, $F(1,118)=22.35, p<.001, \eta^{2}=.16$. Participants in the love condition retrieved nearly twice as many letters than those in the control, $M=3.43, S D=1.51$, vs. $M=1.85, S D=1.74$, respectively, yet the percentage of correct letters retrieved by participants was similar in the two groups. Of the total number of letters the participants recorded, $88.7 \%$ were correct in the love condition, i.e., belonging to the French word amour, and in the control, $88.1 \%$ 
of the letters were correct, i.e., belonging to the word table, signifying that experimental condition had no effect on the percentage of letters falsely retrieved by the participants.

\section{Number of words retrieved}

Two sex X semantic induction analysis of variance indicated that semantic induction had no effect on the number of words retrieved, $F(1,118)=0.28, n s$, or on the number of words correctly retrieved, $F(1,118)=2.99, p=.08, n s$.

\section{General meaning attributed to the letters and words briefly presented in a random order}

In the love condition, 18 out of 62 participants identified the general meaning of the letters and words correctly, with four stating that the theme was about "feelings". Seven other participants stated there was a general meaning, but did not know what it was and three others stated that the general meaning of the letters and words concerned the extinction of dinosaurs. A single participant believed the theme was about education. In the control, seven participants believed there was a general meaning without knowing what it was, one stated it concerned the extinction of dinosaurs, and one claimed it was about personality. In short, 33 participants $(53.2 \%)$ in the love condition had the impression that the letters and words had a general meaning, compared to only nine $(15.0 \%)$ in the control, $\chi^{2}(1, N=122)=19.74$, $p<.001, \Phi=.40$.

In the experimental group, $20(44.4 \%)$ of the females stated that the general meaning concerned love or feelings, whereas only two $(11.7 \%)$ of the males reached the same conclusion, $\chi^{2}(1, N=62)=5.76, p=.01, \Phi=.30$. Furthermore, in this group, 12 participants understood the general meaning (love) only after they had written down the letters they could retrieve. Some noted that these letters were an anagram of the word amour (e.g., ruoma). However, five participants correctly retrieved all the letters, but did not conclude that they had a general meaning nor identified the anagram. In contrast, none of the participants in the control group, even those two who correctly retrieved all five letters of the word table, declared that these letters formed a word.

\section{Awareness of the concept of love}

Within the love group, we compared participants ( $n=$ 22) who were aware of the general meaning of the words and letters to those $(n=40)$ who were unaware of this meaning or did not write it down: macrostructure $M=4.54(S D$ $=1.26)$ vs. $M=4.90(S D=1.05)$, respectively, $t=1.17$, $n s$; argumentation $M=3.95(S D=0.95)$ vs. $M=4.40(S D=$ $0.81), t=1.94, p=.056, d=0.050 ;$ microstructure $M=4.81$ $(S D=0.95)$ vs. $M=4.85(S D=0.73), t=0.14, n s$.

\section{DISCUSSION}

These findings indicate that participants who were semantically induced with love had better recall compared to participants in the control condition. They also showed greater interest in the problem-solution text. Contrary to Förster, Epstude, \& Özelsel (2009) and Förster, Özelsel, \& Epstude (2010), we did not intend to measure creative or holistic processing. Our procedure did not imply perception and preferences for figures, but memory. However, if the priming of love enhances global processing and impairs detail-oriented processing, we might have expected participants primed with love, compared to a neutral word, to perform better at the macrostructure and argumentation levels of comprehension but not at the microstructure level. This was not the case: those primed with love, compared to the control, performed better at the deepest, global comprehension level of argumentation, and also for the detail-oriented questions of microstructure, that do not involve complex reasoning but rather recall of peripheral details. In addition, we found that among participants induced with the idea of love, those who were aware of it had lower recall performance at the argumentation level, but not with respect to macrostructure or microstructure. This result fits the hypothesis that the idea of love would capture participants' attention and be detrimental to task performance, but only on a deep level of text processing.

One possible path to explain our findings is that the concept of love triggered emotional interest, which, in turn, enhanced recall. Additionally, the emotional component of the concept of love might have been misinterpreted and erroneously attributed to the problem-solution text. Previous research stated that "affect that has no salient object tends to be experienced as a reaction to whatever is in mind at the time" (Clore \& Storbeck, 2006, p. 124). Moreover, "for positive emotions, in the absence of a specific target of emotion, the ambient characteristics take on greater importance and one attends to and later recalls more of these peripheral details" (Talarico et al., 2009, p. 393). As we have seen above, our experiment was designed to focus participants' attention outside the possible meaning of the scrambled letters. Only one third of participants in the love condition (22 out of 62) was aware of the concept of love, or at least wrote it down. It is also plausible that some participants recognised the concept of love only after they retrieved the scrambled letters and discovered the anagram, at the very end of the experiment. Previous research has shown that individuals asked to learn a scientific demonstration to which emotionally interesting text was added, tend to be distracted from relevant information (Harp \& Mayer, 1997). Conversely, our findings support the view that priming the idea of love may facilitate cognitive processing when participants do not have a strong awareness of the presence of emotional stimuli and, consequently, of the real cause of the interest they feel towards the current task. Thus, spatial and tem- 
poral proximity between affective cues and a learning task may occur without being detrimental to text recall.

In the present study, in the love condition, there was no overall effect of the awareness of the meaning of the letters A.M.O.U.R on text retrieval. Those who were aware of this meaning, however, tended to show decreased performance on the argumentation level. Therefore, more work is needed to test the possibility that, when aware of the concept of love, individuals can allocate less cognitive resources to the current task, which would impair complex (argumentation), more than superficial (microstructure) reasoning.

The broaden-and-build theory (Fredrickson, 2001) assumes that love, like other positive emotions, broadens people's momentary thought-action repertoires. People experiencing positive emotions tend to be more creative, open-minded, cognitively flexible, and integrative. That is, not only do positive emotions elicit a heuristic, global processing of ongoing information, they also foster interest for new information, including seemingly peripheral details. Thus, love may trigger both global processing and analytic, detail-oriented processing. Indeed, recent work showed that positive emotions enhance recall of peripheral information (Talarico et al., 2009), and that emotion words are processed faster and more efficiently than neutral ones, consistent with the view that they capture and sustain attention (Kousta, Vinson, \& Vigliocco, 2009). It is noteworthy that in our initial sample, 22 participants out of 62 primed with love guessed the general meaning of the single letters was love, whereas none of the 60 participants primed with table guessed they had seen the letters that compose the word table.

\section{EXPERIMENT 2}

A limitation of Study 1 was the absence of measurement of a possible shift in participants' affective state, due to the semantic induction of love. It can be argued that our results were due to the positive valence of the word love and of the words that were associated with it. Participants would have been influenced to be in a positive mood, and thus, would show more interest and motivation towards the task at hand. In line with this reasoning, our results would not be specific to the concept of love, but would possibly be triggered by the mere activation of a positive mood. We believe, however, that this explanation is erroneous. Recent research has found that positive mood tends to be associated with global, heuristic information processing, whereas negative mood is associated with detail-oriented, analytic information processing (Bless \& Fiedler, 2006; Storbeck \& Clore, 2007).

Several studies have found positive mood to impair memory, and negative mood to increase it. For example, event-based prospective memory is increased when participants are in a sad mood (Rummel, Hepp, Klein, \& Silberleitner, 2012); weather-induced bad mood increases recall and recognition memory (Forgas, Goldenberg, \& Unkel- bach, 2009); negative mood is also associated with better identification of misinformation regarding previously encoded information (Hess, Popham, Emery, \& Elliott, 2012); positive mood impairs working memory (Martin \& Kerns, 2011). Thus, it seems unlikely that the induction of love would have triggered positive emotion, which in turn would have increased recall performance. Moreover, Corson and Verrier (2007) found that false memories are increased by discrete emotions whatever their valence: participants induced to high-arousal emotions, whether positive or negative (happiness vs. anger), have more false memories than participants induced with low-arousal, positive or negative emotions (serenity vs. sadness). Therefore, the positive valence of the word love is unlikely to explain the results of Study 1.

It remains that we need to check for a possible influence of the semantic induction of love on participants' mood. The second purpose of this study was to make sure the effects found in Study 1 may generalize to other texts as well. In addition, this study was designed to overcome a limitation of Study 1, i.e., the fact that it did not allow us to ensure that the results were due (a) to the induction of the letters that compose the word love, (b) to the induction of the associated words, and among them, which of them particularly? This is the reason why, in Study 2, participants were semantically induced merely with the word love. Moreover, this word was displayed from the beginning to the end of the experiment. It was expected that, if displayed independently of any romantic context, the word love would keep its power as an attention magnet without impairing cognitive processing.

\section{METHOD}

\section{Participants}

The sample consisted of 193 undergraduate Business students (75 male) from the University of South Paris, France, aged 18 and 19. These students belonged to eight groups (ranging in size from 20 to 26), and these groups were randomly assigned to either the experimental (love) condition (4 groups) or the control condition (4 groups). A preliminary analysis showed that there were no significant differences in the grades obtained by the participants in the experimental versus the control condition, with respect to their university courses during the semester at the time of the experiment.

\section{Materials}

We used a Flash Conso video sequence of a TV series broadcasted daily on French public TV channels such as France2, France 3 and FranceÔ. It consists of brief information on products and consumer traps with target audience 
consumers. We used a Flash Conso lasting 1 minute 38 seconds, in which 8 " at the beginning and 5" at the end visually and musically identify the series. This Flash Conso was entitled Conference on waste collection: To turn old out of new. As a general outline, it stated that (a) a conference on waste collection had taken place in Paris, (b) the companies attending it observed that France is still behind in this matter, (c) green containers for glass and yellow containers for cardboard and plastics should at least be made more common, (d) the cost of biodegradable waste collection should be very low for local authorities, and (e) local waste reception centers should be instituted. Overall, the information displayed in this video is very short and descriptive and doesn't allow deep-reasoning questions. Therefore we set up three factual, single-choice questions: Q1, "In which city did the conference about waste processing take place?"; Q2, "How many companies are specialized in waste collection?"; and Q3, "Is the collection of food waste costly?".

\section{Procedure}

Participants were first informed that the "survey" in which they had accepted to participate was commissioned by the Centre Technique Régional de la Consommation (the federation of all the consumer associations of the Ile-deFrance [Paris] area). The experimenter stated that the aim of the survey was to determine which type of information is easily memorized by the consumers. He then mentioned the name of the global project to which this study belonged and wrote this name on a board in uppercase. Thus, the alleged name of this project remained visible throughout the study. In the experimental condition the name was "AIMER POUR S'INFORMER" ("Love in order to be informed") whereas in the control condition the name was "POUR S'INFORMER" ("In order to be informed"). Students were then informed that a video would be displayed and that they would have to memorize its content to their best, before being asked questions about its content. The Flash Conso was then projected on an overhead screen $(2 \times 1.70 \mathrm{~m})$. Right after the projection had ended, participants completed a mood check ("How do you feel right now?") with anchors of 1 $=$ negative and $7=$ positive. They were then asked to rate how interested, involved, bored, happy, scared, annoyed, and guilty they felt after watching the Flash Conso, on a 7 -point Likert scale $(1=$ not at all, $7=$ very much $)$. Finally, they answered the three recall questions.

\section{RESULTS}

\section{Mood effects}

A $2(\operatorname{sex}) \times 2$ (semantic induction) multivariate analysis of variance on the eight emotional scores yielded no signifi- cant result for sex, $F(8,178)=0.75, p=.64$, for semantic induction, $F(8,178)=1.05, p=.39$, nor for interaction, $F(8$, $178)=1.34, p=.22$. Post hoc analysis (Fischer LSD tests) indicated that sex had no significant influence on any of the emotional scores and that semantic induction had no significant effect on the emotional scores, except for the interest regarding the video. Further analysis revealed that participants induced with the idea of love were more interested in the video, $M=3.88, S D=0.15$, than participants in the control group, $M=3.31, S D=0.16$, but this is a small effect size, $t(191)=2.22, p=.027, d=0.32$.

\section{Recall performance}

Our chief prediction was that the idea of love would entail higher levels of motivation which, in turn, would enhance recall performance. We used log-linear analysis and chi-square tests for the analysis of data. The log-linear analysis showed no main effect of sex or semantic induction on recall performance, and no interaction effect between sex, semantic induction, and interest regarding the video. Interest had a significant effect on recall performance for two out of the three questions: Q1 ("In which city did the conference about waste processing take place?") and Q3 ("Is the collection of food waste costly?"). To specify these effects, the interest, ordinal scale, was broken down into two discrete categories: interest above or equal to the median, and interest beneath the median. Analysis revealed that among participants who were interested in the video, $53(50.4 \%)$ retrieved the right answer for Q1, whereas among participants who were not interested in the video, only $25(28.4 \%)$ retrieved the right answer: $\chi^{2}(1, N=193)=9.68, p<.01, \Phi$ $=.22$. Among participants who were interested in the video, $59(56.2 \%)$ retrieved the right answer for Q3, as compared to $37(42.0 \%)$ among participants who were not interested in the video, $\chi^{2}(1, N=193)=3.83, p=.05, \Phi=.14$. Regarding Q2, results did not reach the significance level, $\chi^{2}(1, N=$ $193)=1.87, p=.17, n s$.

\section{DISCUSSION}

One important point was to clarify the influence of the semantic induction of love on emotional states. Results showed that this influence was limited to interest. Participants induced with the concept of love, as compared to the control group, were more interested in the video. In contrast, love did not appear to influence participants to experience a happy mood. This is an important indication for explaining the effects of love on recall. Study 2 also indicates that interest increased recall performance for two out of the three questions. The main flaw of this study, however, was probably the briefness of the information video being displayed to the participants, and therefore the small number of questions it allowed. We had only three discrete questions but no 
reliable scale. This might be the reason why we found no consistent link between love and recall performance. Further demonstration of the influence of the concept of love on information processing and retrieval would thus be needed.

\section{EXPERIMENT 3}

In Study 1 and 2 we had deliberately chosen materials with low interest to Business students in order to allow the semantic induction of love to reinforce the level of emotional interest. In this study, we wanted to broaden our investigation to a context of increased interest regarding the material, and to see whether the pattern of results found in Study 1 and 2 would hold in this context. Study 3 also afforded us the opportunity to generalize our findings to a different text.

\section{METHOD}

\section{Participants}

Participants (24 male and 27 female) were passersby wandering on their own in a park (Parc de Sceaux near Paris) and who accepted to participate in a survey about consumer information.

\section{Materials}

We used a 610 word information leaflet concerning food allergens, with six subheadings: "How to be aware of food allergens?", "Which allergens?", "Allergen labelling", "When allergens are present by chance", "How to understand labels", "Additional information". This leaflet is published by the French Treasury Department with its own heading and a second heading "République Française". On this official document we simply added a sticker with a semantic induction similar to the one of Study 2: "AIMER POUR S'INFORMER" (love condition), or "POUR S'INFORMER" (control). Participants who read the leaflet were thus forced to read the semantic induction. Ten questions were set up after preliminary testing of the material, which also confirmed that participants felt interested in this information, mostly due to the fact that it was perceived as helping people to improve their health, and then enabling them to give advice to friends and relatives. The 10 questions were each accompanied with three multiple-choice answers, e.g., "Which of these products doesn't belong to the list of allergens? (a) lentils, (b) fish, (c) celery". As in Study 2 , the official leaflet we used was very factual and led us to keep only questions which involved the microstructure level of comprehension.

\section{Procedure}

The study was carried out by a female student aged 19 , with mean physical attractiveness, as indicated by pre- testing, $M=10.31, S D=1.18$, on a 20 -point scale. She was instructed to approach the first person she met, of an estimated age of 30 to 50 , in a park located $10 \mathrm{~km}$ south of Paris (Parc de Sceaux). The female confederate asked the person she met if he or she would accept to participate in a survey aimed at helping consumers to become more informed. When the person accepted, they were informed that the survey, entitled "Love to be informed" ("To be informed", in the control group), investigated which information is memorized the best by consumers. The information leaflet concerning the food allergens was then given to the participant. They were advised to read it very attentively, knowing that questions would be asked regarding its content. Immediately following the reading task (which generally took 5 to 8 minutes), the participant answered the 10 questions regarding the material, in a set order. Then participants answered two questions similar to those used in Study 2: (a) "How interested did you feel after reading the information leaflet about allergens?", with anchors of $1=$ not at all, and $7=$ very much; and (b) "How do you feel right now?" ( 1 = negative and $7=$ positive $)$. Once the interaction had been completed with a participant, the confederate had the instruction to approach the next person on their own, aged 30 to 50, and to alternate the two semantic inductions all along the study.

\section{RESULTS}

We summed up the answers on the 10 recall questions, allocating one point for each correct answer. A 2 (sex) X 2 (semantic induction) analysis of variance was performed on the total score for recall. A main effect of semantic induction was found, $F(1,47)=14.07, p<.001, \boldsymbol{\eta}^{2}=.23$, but no effect of sex, $F(1,47)=0.00, p=.93, \eta^{2}<.01$. Participants in the love condition retrieved more correct answers, $M=$ $6.37, S D=0.30$, than those in the control group, $M=4.87$, $S D=0.29$. There was also an interaction between semantic induction and sex, $F(1,47)=4.64, p<.05, \eta^{2}=.09$. Post hoc (Fischer LSD) analysis revealed that male participants' recall performance was significantly increased in the love, $M=6.81, S D=0.42$, compared to the control condition, $M=$ $4.46, S D=0.39 ; p<.001$, whereas no significant difference was found for female participants, $M=5.92, S D=0.39$ vs. $M=5.28, S D=0.38$, respectively; $p=.25, n s$.

Similar analysis with interest regarding the information leaflet as the dependent variable revealed no effect of semantic induction, or sex, or interaction. When semantically induced with love, participants' interest was of $M=5.08$ $(S D=0.26)$, as compared to $M=4.70(S D=0.24)$ in the control group. A similar pattern of results was found when the dependent variable was the current mood: $M=6.08$ (SD $=0.19)$ in the love condition, versus $M=5.81(S D=0.18)$ in the control condition. 


\section{DISCUSSION}

In this study, the mere induction of the word love has been found to enhance performance in the recall task. There was no effect of semantic induction on participants' current mood, and neither on interest regarding the information being displayed. It is noteworthy that interest was high $(M=$ 4.88, $S D=0.25$, anchors $1-7)$, as compared to Study $2(M=$ $3.57, S D=0.15$, anchors $1-7)$ and Study $1(M=5.44, S D=$ 0.33 , anchors $0-10)$. Interest regarding the material can be considered low to moderate in Studies 1 and 2, and moderate to high in Study 3. One reason why we found no effect of semantic induction on interest in Study 3 might be that a ceiling effect occurred. If most participants felt an interest regarding the information leaflet, then the semantic induction of love would have no additional effect on interest. It remains, however, that a main effect of induction on recall has been found in Study 3, which cannot be accounted for by the theoretical path we outlined at the beginning of this article, i.e., a direct effect of the idea of love on emotional interest, in turn leading to increased attention and motivation for the task at hand.

\section{GENERAL DISCUSSION}

Our findings indicate that the semantic induction of love had an effect on recall. In Study 1, the induction took place after participants had read the problem-solution text, whereas in Studies 2 and 3 it was both heard and read at the beginning of the study and remained visible throughout the study. Thus it is possible that the induction of love may have influenced only retrieval (Study 1) or both text processing and retrieval (Study 2 and 3). Our results are in line with previous research showing that topic interest is an important predictor of reading comprehension and recall. Hidi (2001) stated that interest leads to better attentional focus on the text, leading to deeper processing. Interest and motivation to perform the task well were also found to decrease mind wandering which, in turn, increases reading comprehension (Unsworth \& McMillan, 2012). In addition, having an interest while reading improves text recall (Schiefele \& Krapp, 1996; Schraw, Bruning, \& Svoboda, 1995).

No previous research, however, has established whether, when induced after reading a text, interest may enhance recall. In Study 1 and 2, as expected, results indicated that inducing love increased participants' interest regarding the information being displayed, in which they had basically little interest. In contrast, Study 3, where participants were basically interested in the text, showed no effect of semantic induction on interest. Therefore, if semantic induction has an effect on recall via interest when the material is basically associated with little interest, an alternative explanation would be needed for high-interest material.

The second explanation for our results would be that the idea of love had an effect on participants' mood, which in turn influenced recall. We have already presented empirical evidence above (Study 2) showing that positive mood impairs memory, and that negative mood enhances memory. Positive mood would elicit reliance on general knowledge structures and heuristic processing, whereas negative mood would elicit in-depth, analytic thinking (Bless \& Fiedler, 2006). If participants induced with love were in a positive mood, their recall performance should therefore be impaired, especially regarding details or microstructure. But we found the opposite. In fact, our results (Study 2 and 3) indicate that the semantic induction of love had no effect on emotional states, except for interest.

Previous research on the semantic induction of love also suggests that results were not due to mood effects. For example, Guéguen, Jacob, and Lamy (2010) found that music's romantic lyrics had an effect on compliance to a courtship request. Two songs were compared, having shown in pre-testing to be liked to the same degree, but to differ only in terms of the impression of romanticism they gave. Thus it cannot be argued that they triggered different moods. Also, Lamy et al. (2008, 2009) and Fischer-Lokou et al. (2009) asked participants to "retrieve a love episode that has meant a great deal" to them, or, in the control group, to "retrieve a piece of music that has meant a great deal" to them. Participants in the love condition were more helpful than those in the control group. Despite the fact that mood effects were not measured, it seems plausible that, if any shift in participants' mood occurred, it would have been positive in both conditions, with no significant difference between conditions. In sum, the present findings as well as previous research do not appear to lend support for a mood explanation.

An alternative explanation to the present findings arises from the statement that discrete emotions elicit an impulse to reach specific goals (Angie, Connelly, Waples, \& Kligyte, 2011; Roseman, Wiest, \& Swartz, 1994; Sabini \& Silver, 2005). For example, fear has the goal of avoiding danger, anger has the goal of altering a negative outcome, sadness has the goal of recovering from loss, jealousy has the goal of retaining one's mate. Emotions have a positive or negative valence, their goals are approach versus avoidance oriented, and these goals are associated with action tendencies, i.e., the activation of approach or withdrawal responses. Anger is a negative emotion, but it entails an approach motivation towards a threat or an enemy. Disgust is a negative emotion with a motivation for avoidance. Pride is a positive emotion with an approach tendency, whereas shame is negative and has an avoidance tendency. Depending on the authors, love has been conceptualized, or not, as a basic emotion. It fits closely, however, to the definition of an emotion schema, i.e., "an evolved feeling plus learned labels and concepts" (Izard, 2007, p. 265). Like other emotions and emotion schemas, it should entail a motivation for action, goal-oriented component. No previous research, however, has delineated this component with any accuracy. Thus we can only speculate that the evolved component of love 
might elicit an approach-oriented motivation, the desire to get in touch and maintain positive relationships, together with an interest component that arises out of the discovery of something novel, exciting, and rewarding. Therefore, the induction of love might have automatically activated an approach-oriented behavior towards the materials at hand, with increased attention and deeper processing. Once the current information becomes goal-relevant, it benefits from increased accessibility in memory (Levine \& Edelstein, 2009). This theoretical explanation remains speculative, and other research will be needed to explore it further.

This research was the first attempt to investigate the possible links between the semantic induction of love and memory retrieval. We found that, when induced independently of any romantic context, the idea of love enhanced recall of information. Future research will need to determine the effects of love when clearly associated with the idea of romance, and thus potentially detrimental to text processing and retrieval. Further research is also needed to enlighten the specific goals love would entail, and its association with increased arousal, activation and motivation.

\section{REFERENCES}

Angie, A. D., Connelly, S., Waples, E. P., \& Kligyte, V. (2011). The influence of discrete emotions on judgement and decision-making: A meta-analytic review. Cognition and Emotion, 25, 1393-1422. doi:10.1080/0 2699931.2010.550751

Aron, A., Fisher, H. E., Strong, G., Acevedo, B., Riela, S., \& Tsapelas, I. (2008). Falling in love. In S. Sprecher, A. Wenzel, \& J. Harvey (Eds.), Handbook of relationship initiation (pp. 315-336). New York, NY: Psychology Press.

Bargh, J. A., Chen, M., \& Burrows, L. (1996). Automaticity of social behavior: Direct effects of trait construct and stereotype activation on action. Journal of Personality and Social Psychology, 71, 230-244. doi:0022-3514/96/ S3.00

Bless, H., \& Fiedler, K. (2006). Mood and the regulation of information processing and behavior. In J. P. Forgas (Ed.), Affect in social thinking and behavior (pp. 6584). New York, NY: Psychology Press.

Clore, G. L., \& Storbeck, J. (2006). Affect as information about liking, efficacy, and importance. In J. P. Forgas (Ed.), Affect in social thinking and behavior (pp. 123141). New York, NY: Psychology Press.

Corson, Y., \& Verrier, N. (2007). Emotions and false memories: Valence or arousal? Psychological Science, 18, 208-211.

Coy, B., O’Brien, W. H., Tabaczynski, T., Northern, J., \& Carels, R. (2011). Association between evaluation anxiety, cognitive interference and performance on working memory tasks. Applied Cognitive Psychology, 25, 823832. doi:10.1002/acp.1765

Dovidio, J. F., \& Penner, J. A. (2001). Helping and altruism. In G. J. O. Fletcher \& M. S. Clark (Eds.), Blackwell handbook of social psychology: Interpersonal processes (pp. 162-195). Malden, MA: Blackwell.

Ellis, H. C., \& Ashbrook, P. W. (1988). Resource allocation model of the effects of depressed mood states on memory. In K. Fiedler \& J. Forgas (Eds.), Affect, cognition, and social behaviour (pp. 25-43). Toronto: Hogrefe.

Ellis, H. C., Moore, B. A., Varner, L. J., Ottaway, S. A., \& Becker, A. S. (1997). Depressed mood, task organization, cognitive interference, and memory: Irrelevant thoughts predict recall performance. Journal of Social Behavior and Personality, 12, 453-470. doi:415/9241612

Fischer-Lokou, J., Lamy, L., \& Guéguen, N. (2009). Induced cognitions of love and helpfulness to lost persons. Social Behavior and Personality, 37, 1213-1220. doi:10.224/sbp.2009.37.9.1213

Fitzsimons, G. M., \& Bargh, J. A. (2003). Thinking of you: Nonconscious pursuit of interpersonal goals associated with relationship partners. Journal of Personality and Social Psychology, 84, 148-164. doi:10.1037/00223514.84.1.148

Forgas, J. P., Goldenberg, L., \& Unkelbach, C. (2009). Can bad weather improve your memory? An unobtrusive field study of natural mood effects on real-life memory. Journal of Experimental Social Psychology, 45, 254257. doi:10.1016/j.jesp.2008.08.014

Förster, J., Epstude, K., \& Özelsel, A. (2009). Why love has wings and sex has not: How reminders of love and sex influence creative and analytic thinking. Personality and Social Psychology Bulletin, 35, 1479-1491. doi:10.1177/0146167209342755

Förster, J., Özelsel, A., \& Epstude, K. (2010). How love and lust change people's perception of relationship partners. Journal of Experimental Social Psychology, 46, 237246. doi:10.1016/j.jesp.2009.08.009

Fredrickson, B. L. (2001). The role of positive emotions in positive psychology. The broaden-and-build theory of positive emotions. American Psychologist, 56, 218226. doi:10.1037//0003-066X.56.3.218

Guéguen, N., Jacob, C., \& Lamy, L. (2010). 'Love is in the air': Effects of songs with romantic lyrics on compliance with a courtship request. Psychology of Music, 38, 303-307. doi:10.1177/0305735609360428

Harp, S. F., \& Mayer, R. E. (1997). The role of interest in learning from scientific text and illustrations: On the distinction between emotional interest and cognitive interest. Journal of Educational Psychology, 89, 92-102. doi:0022-0663/97/S3.00 
Hess, T. M., Popham, L. E., Emery, L., \& Elliott, T. (2012). Mood, motivation, and misinformation: Aging and affective state influences on memory. Aging, Neuropsychology, and Cognition, 19, 13-34. doi:10.1080/13825 585.2011 .622740

Hidi, S. (2001). Interest, reading, and learning: Theoretical and practical considerations. Educational Psychology Review, 13, 191-209. doi:1040-726X/01/09000191S19.50/0

Huang, Y. M., Baddeley, A., \& Young, A. W. (2008). Attentional capture by emotional stimuli is modulated by semantic processing. Journal of Experimental Psychology: Human Perception and Performance, 34, 328-339. doi:10.1037/0096-1523.34.2.328

Ihssen, N., \& Keil, A. (2009). The costs and benefits of processing emotional stimuli during rapid serial visual presentation. Cognition and Emotion, 23, 296-326. doi:10.1080/02699930801987504

Izard, C. E. (2007). Basic emotions, natural kinds, emotion schemas, and a new paradigm. Perspectives on Psychological Science, 2, 260-280.

Kintsch, W. (1980). Learning from texts, levels of comprehension, or: Why anyone would read a story anyway. Poetics, 9, 87-98.

Kintsch, W., \& van Dijk, T. A. (1978). Toward a model of text comprehension and production. Psychological Review, 85, 363-394.

Kousta, S.-T., Vinson, D. P., \& Vigliocco, G. (2009). Emotion words, regardless of polarity, have a processing advantage over neutral words. Cognition, 112, 473-481. doi:10.1016/j.cognition.2009.06.007

Lamy, L., Fischer-Lokou, J., \& Guéguen, N. (2008). Semantically induced memories of love and helping behavior. Psychological Reports, 102, 418-424. doi:10.2466/ PR0.102.2.418-424

Lamy, L., Fischer-Lokou, J., \& Guéguen, N. (2009). Induced reminiscence of love and chivalrous helping. Current Psychology, 28, 202-209. doi:10.1007//s12144-0099059-9

Lamy, L., Fischer-Lokou, J., \& Guéguen, N. (2010). Valentine street promotes chivalrous helping. Swiss Journal of Psychology, 69, 169-172. doi:10.1024/1421-0185/ a000019

Laney, C., Campbell, H. V., Heuer, F., \& Reisberg, D. (2004). Memory for thematically arousing events. Memory and Cognition, 32, 1149-1159.

Leopold, C., \& Leutner, D. (2012). Science text comprehension: Drawing, main idea selection, and summarizing as learning strategies. Learning and Instruction, 22, 1626. doi: 10.1016/j.learninstruc.2011.05.005

Levine, L. J., \& Edelstein, R. S. (2009). Emotion and memory narrowing: A review and goal-relevance approach. Cognition and Emotion, 23, 833-875. doi:10.1080/02699930902738863

Martin, E. A., \& Kerns, J. G. (2011). The influence of positive mood on different aspects of cognitive control. Cognition and Emotion, 25, 265-279. doi:10.1080/026 99931.2010.491652

Meyer, D. E., \& Schvaneveldt, R. W. (1971). Facilitation in recognizing pairs of words: Evidence of a dependence between retrieval operations. Journal of Experimental Psychology, 2, 227-234.

Mikulincer, M., Hirschberger, G., Nachmias, O., \& Gillath, O. (2001). The affective component of the secure base schema: Affective priming with representations of attachment security. Journal of Personality and Social Psychology, 81, 305-321. doi:10.1037/00223514.81.2.305

Neely, J. H. (1976). Semantic priming and retrieval from lexical memory: Evidence for facilitatory and inhibitory processes. Memory and Cognition, 4, 648-654.

Querrioux-Coulombier, G. (1988). Chronopsychologie et niveaux de traitement: des tâches de vigilance aux tâches de compréhension [Chronopsychology and treatment levels: Vigilance tasks to comprehension tasks ] (Unpublished doctoral thesis). Université de Poitiers.

Roseman, I. J., Wiest, C., \& Swartz, T. S. (1994). Phenomenology, behaviors, and goals differentiate discrete emotions. Journal of Personality and Social Psychology, 67, 206-221. doi:0022-3514/94/S3.00

Rossi, J. P., \& Bert-Erboul, A. (1991). Sélection des informations importantes et compréhension de textes [Selection of important information and reading comprehension]. Psychologie Française, 36, 135-142.

Rummel, J., Hepp, J., Klein, S. A., \& Silberleitner, N. (2012). Affective state and event-based prospective memory. Cognition and Emotion, 26, 351-361. doi:10 $.1080 / 02699931.2011 .574873$

Sabini, J., \& Silver, M. (2005). Ekman's basic emotions: Why not love and jealousy? Cognition and Emotion, 19, 693-712. doi:10.1080/02699930441000481

Schiefele, U., \& Krapp, A. (1996). Topic interest and free recall of expository text. Learning and Individual Differences, 8, 141-160. doi:10.1016/S10416080(96)90030-8

Schraw, G., Bruning, R., \& Svoboda, C. (1995). Sources of situational interest. Journal of Reading Behavior, 27, $1-17$.

Storbeck, J., \& Clore, G. L. (2007). On the interdependence of cognition and emotion. Cognition and Emotion, 21, 1212-1237. doi:10.1080/02699930701438020

Talarico, J. M., Berntsen, D., \& Rubin, D. C. (2009). Positive emotions enhance recall of peripheral details. Cognition and Emotion, 23, 380-398. doi:10.1080/02699930801993999 
Unsworth, N., \& McMillan, B. D. (2012). Mind wandering and reading comprehension: Examining the roles of working memory capacity, interest, motivation, and topic experience. Journal of Experimental Psychology: Learning, Memory, and Cognition, 39(3), 832-842. doi:10.1037/a0029669

Wolfe, M. B., \& Woodwyk, J. M. (2010). Processing and memory of information presented in narrative or expos- itory texts. British Journal of Educational Psychology, 80, 341-362. doi: 10.1348/000709910X485700

Zemack-Rugar, Y., Bettman, J., \& Fitzsimons, G. J. (2007).

The effects of nonconsciously priming emotion concepts on behavior. Journal of Personality and Social Psychology, 93, 927-939. doi:10.1037/0022-3514.93.6.927 